\title{
Proceeding
}

7th INSHS International Christmas Sport Scientific Conference, 9-12 December 2012. International Network of Sport and Health

Science. Szombathely, Hungary

\section{Comparison of selected characteristics of gait in men and women}

\author{
JAN DOŠLA , PAVEL KORVAS, MARTIN ZVONAŘ, RADEK MUSIL, JAN ŠENKÝŘ, TOMÁŠ KALINA
}

Faculty of Sports Studies, Masaryk University, Brno, Czech Republic

\begin{abstract}
Došla J, Korvas P, Zvonař M, Musil R, Šenkýr J, Kalina T. Comparison of selected characteristics of gait in men and women. J. Hum. Sport Exerc. Vol. 8, No. Proc2, pp. S114-S119, 2013. In this research, we have attempted to find out and compare selected characteristics of gait in men and women; 20 men and 20 women aged 30-39 were observed. The average age of men was 34.0 years, of women 34.1 years respectively. For measuring, pressure shoe insoles were used (Pedar Mobile, Novel Munich, 99 sensors, $100 \mathrm{~Hz}$ ). Each person had three attempts: two trial attempts, the third one was measured. For observation, we selected three stances of each leg, always between the third and eighth stride. Significant differences between men and women were found in stance duration in the active part of stance while the passive part of stance was similar. With applied force (F1, F2, F3) during stance, after recalculating per a kilogram of weight, no statistically significant differences were found. No significant differences between the right and left legs were found either. Key words: GAIT, PEDAR, ACTIVE PART OF STANCE, PASSIVE PART OF STANCE.
\end{abstract}

Corresponding author. Údolní 3, Brno 602 00, Czech Republic.

E-mail: dosla@fsps.muni.cz

7th INSHS International Christmas Sport Scientific Conference, 9-12 December 2012. International Network of Sport and Health Science. Szombathely, Hungary.

JOURNAL OF HUMAN SPORT \& EXERCISE ISSN 1988-5202

(c) Faculty of Education. University of Alicante

doi:10.4100/jhse.2012.8.Proc2.15 


\section{INTRODUCTION}

The significance of walking as a motor activity in today's dehumanized world is still growing. It is necessary to deal with walking not only as a means to increase physical fitness; it is also important to study its quality. Some physical features such as obesity have a significant influence on the distribution of plantar pressures (Hills et al., 2001; Dowling et al., 2004). Static and dynamic characteristics of the foot change not only in children (Müller et al., 2011) but in adults as well (Korvas et al., 2012). In foot area, vertical forces during walking can be measured with different devices. One of the most frequently used devices is Pedar or various force plates. Some studies comparing the use of Pedar agree on different results when different devices are sued for measuring (Boyd et al., 1997). Our study compares selected parameters of gait in men and women aged 30-39.

\section{MATERIAL AND METHODS}

In our research, 20 men and 20 women aged 30-39 were observed. The average age of men was 34.0 years, of women 34.1 years respectively. Average BMl was 25.0 for men and 23.0 for women. Persons from common population were measured, with no serious health problems which could affect the results of the measuring.

Table 1. Men characteristics

\begin{tabular}{lccccc}
\multicolumn{1}{c}{ Variable } & Valid N & Mean & Minimum & Maximum & Std.Dev. \\
\hline Age & 20 & 33.9500 & 30.0000 & 37.5000 & 2.52764 \\
Height & 20 & 182.7550 & 173.5000 & 196.0000 & 6.49579 \\
Weight & 20 & 83.7150 & 67.3000 & 106.1000 & 11.84084 \\
BMl & 20 & 24.9700 & 21.1000 & 30.2000 & 2.59029 \\
\hline \multicolumn{5}{r}{} \\
\hline
\end{tabular}

For measuring, pressure shoe insoles were used (Pedar Mobile, Novel Munich, 99 sensors, $100 \mathrm{~Hz}$ ). Each person had three attempts: two trial attempts; the third one was measured. For observation, we selected three stances of each leg, always between the third and eighth stride. We compared four force parameters: F1 - maximal vertical ground reaction force peak during absorption stage (loading response, LR), F2 lowest force during decline between both peaks, F3 - maximal vertical ground reaction force peak during propulsive stage (terminal stance, TSt), Fm - average vertical force of whole stance. Individual force characteristics (F1, F2, F3) of vertical ground reaction were recalculated in percentage of body weight. Further, we compared four time characteristics: $\mathrm{t}$ - time of whole stance, $\mathrm{t} 1$ - time of absorption stage, $\mathrm{t} 2$ time of propulsive stage, t2/t1 - ratio between time of propulsive stage and time of absorption stage. We compared differences between men and women as well as differences between the right and left legs. For statistics, we used analysis of variance (ANOVA) and Fisher's post hoc LSD test. The level of $5 \%$ was set as a limit for statistically significant differences $(p=0.05)$. 
Table 2. Women characteristics.

\begin{tabular}{lccccc}
\multicolumn{1}{c}{ Variable } & Valid N & Mean & Minimum & Maximum & Std.Dev. \\
\hline Age & 20 & 34.1200 & 31.0000 & 38.4000 & 2.420874 \\
Height & 20 & 166.4300 & 152.0000 & 182.0000 & 6.330552 \\
Weight & 20 & 63.9450 & 49.5000 & 86.2000 & 8.969919 \\
BMI & 20 & 23.0450 & 18.8000 & 27.1000 & 2.37984 \\
\hline \multicolumn{5}{l}{ Gender=F Descriptive Statistics (data) Exclude condition: V2='L' $^{\prime}$}
\end{tabular}

\section{RESULTS}

We have succeeded in proving statistically significant differences with two time characteristics First significant differences between men and women were found in the duration of the whole stance $(\mathrm{t})$. The average duration of stance was 0.69 second in men and 0.64 second in women.

Table 3. Statistical comparison of stance duration in men and women

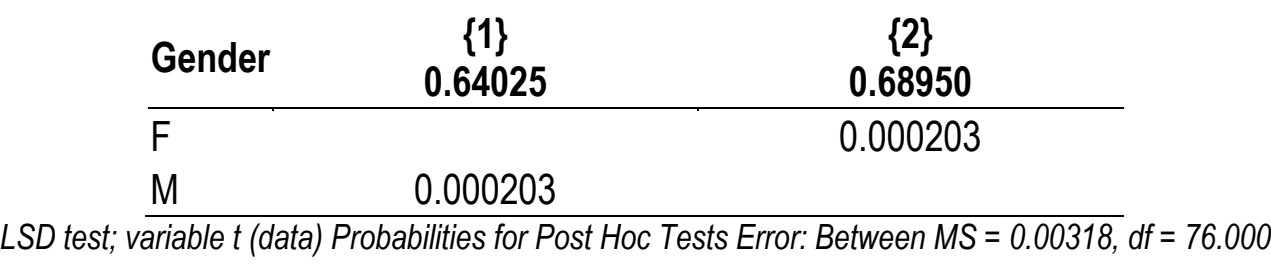

gender; Unweighted Means Wilks lambda $=, 30576, F(14,63)=10,218, p=, 00000$

Effective hypothesis decomposition

Vertical bars denote $+/$ - standard errors

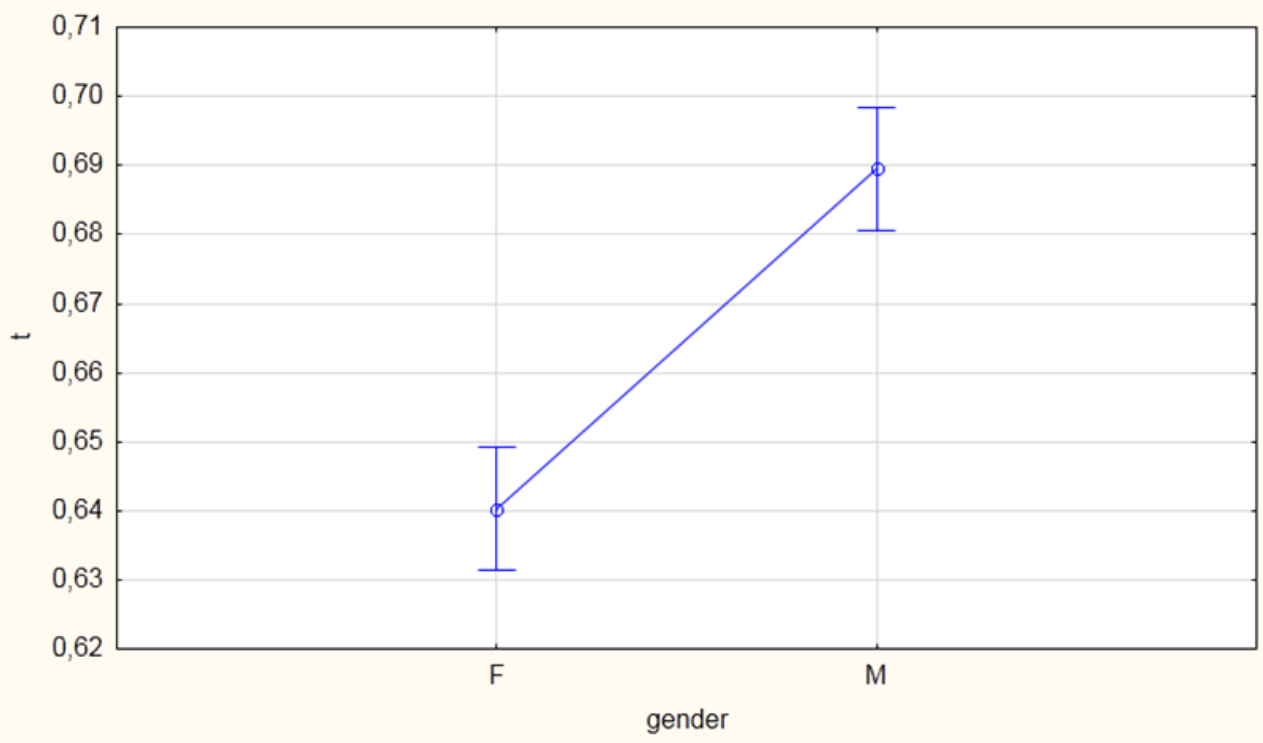

Figure 1. Differences between men and women in stance duration 
Another statistically significant difference was found out in the duration of active part of stance (t2). The average duration of the active part of stance was 0.37 second in men and 0.34 second in women.

Table 4. Comparison of active part of stance duration in men and women

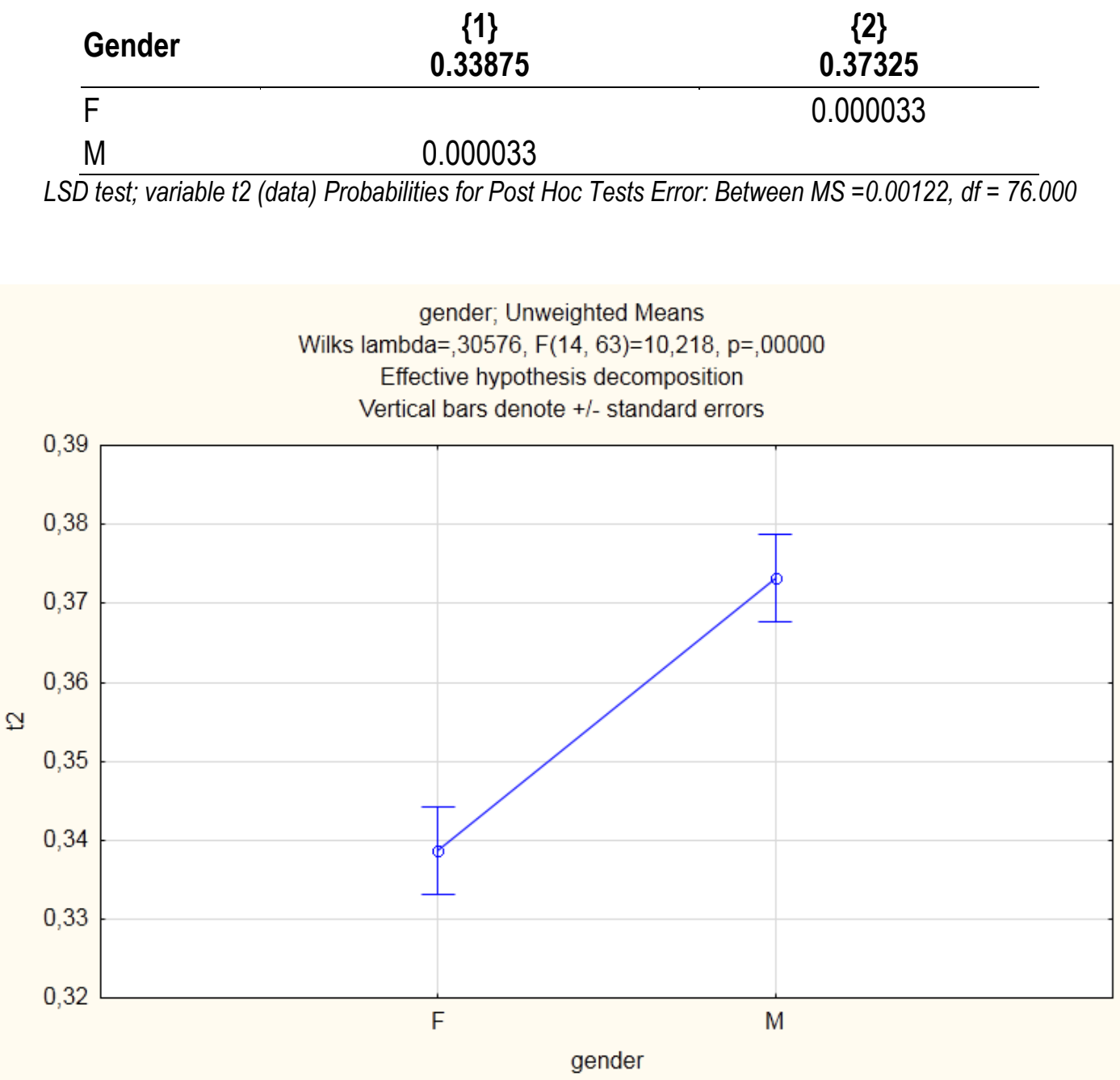

Figure 2. Differences between men and women in active part of stance duration

In the passive part of stance no statistically significant differences were found. In average, the passive part of stance lasted for 0.32 second in men and 0.31 second in women.

With applied force (F1, F2, F3) during stance, no statistically significant differences were found. The average vertical force after recalculation into percentage of body weight was for $\mathrm{F} 1113 \%, \mathrm{~F} 275 \%$ and $\mathrm{F} 3$ $120 \%$. The values measured in women were for $\mathrm{F} 1111 \%$, F2 74\% and F3 118\%.

Values close to the $5 \%$ level of significance were measured also for $t 2 / t 1$ when there was $p=0.06$ when men and women were compared. The value was 1.19 in men and 1.12 in women. 
Table 5. Differences between men and women at t2/t1

\begin{tabular}{|c|c|c|c|}
\hline Cell No. & Gender & $\begin{array}{c}\{1\} \\
1.1221\end{array}$ & $\begin{array}{c}\{2\} \\
1.1868\end{array}$ \\
\hline 1 & $\mathrm{~F}$ & & 0.059963 \\
\hline 2 & M & 0.059963 & \\
\hline
\end{tabular}

gender; Unweighted Means Wilks lambda $=, 30576, F(14,63)=10,218, p=, 00000$

Effective hypothesis decomposition

Vertical bars denote $+/$ - standard errors

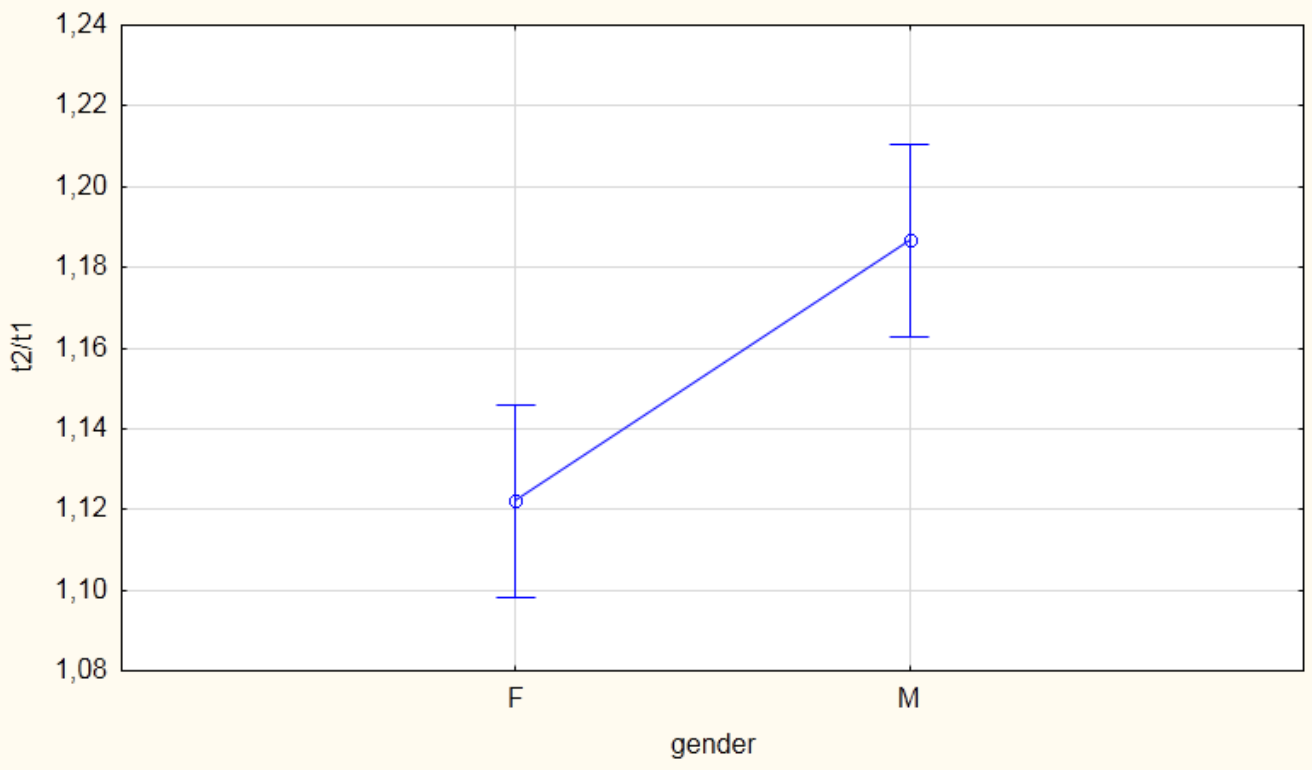

Figure 3. Differences between men and women at t2/t1

\section{DISCUSSION}

In our research, we focused on the selected characteristics of gait in men and women. We have examined force and time characteristics of gait using Pedar pressure insoles. We have not succeeded in finding statistically significant differences when comparing the right and left feet, neither in men nor women. This result could have been expected in healthy persons. Also, when comparing all vertical force characteristics $(F 1, F 2, F 3, F m)$ after recalculation into the percentage of body weight no statistically significant differences were found. Bigger vertical force was found in the active part of stance (F3) both in men and women.

Statistically significant differences between men and women were found in the active part of stance and during measuring the whole stance. In the passive part of stance, no statistically significant differences were found. Duration of stance in men was by 0.04 second longer than in women (men 0.69 second, women 0.65 second). The first part of stance (passive part) in men was by 0.01 second longer than in women (men 0.32 second, women 0.31 second), while the other part of stance (active part) in men was by 0.03 second longer than in women (men 0.37 second, women 0.34 second). 
When we compared the active and passive parts of stance (t2/t1), a higher value was measured in men (1.19) than in women (1.12). This result was close to the $5 \%$ level of probability $(P=0.06)$.

\section{CONCLUSIONS}

The main difference between men and women was measured in the active part of stance, which lasted longer in men. Alike, stance duration in men was statistically significantly longer than in women. Differences between men and women in vertical forces were only in absolute values; after recalculating into the percentage of body, no significant differences were found.

The ration of the active and passive parts of stance was higher in men than in women and it was only slightly below the $5 \%$ level of probability.

The paper is the result of research project: "Creating a research team for the purpose of determining the level of physical activity (inactivity) in selected age groups of the population of men and women in the Czech Republic" (CZ.1.07/2.3.00/20.0044). The project is financed by the European Social Fund and the state budget of the Czech Republic.

\section{REFERENCES}

1. BOYD LA, BONTRAGER EL, MULROY SJ, PERRY J. The reliability and validity of the novel Pedar system of in-shoe pressure measurement during free ambulation. Gait \& Posture, 1997; 5(2):165.

2. DOWLING AM, STEELE JR, BAUR LA. What are the effects of obesity in children on plantar pressure distributions? International Journal of Obesity, 2004; 28(11): 1514-9.

3. HILLS AP, HENNING E, MCDONALD M, BAR-OR O. Plantar pressure differences between obese and non-obese adults: a biomechanical analysis. International Journal of Obesity, 2001; 25(11):1674-9.

4. KORVAS P, MUSIL R, DOSLA J, CACEK J. Cross-sectional comparison of selected gait characteristics of women of different ages. European Association for Sport Management; 2012.

5. MULLER S, CARLSOHN A, MULLER J, BAUR H, MAYER F. Static and dynamic foot characteristics in children aged 1-13 years: A cross-sectional study. Gait \& Posture, 2011; 35(3):389-94. 